\title{
The influence of primary health care professionals in encouraging exercise and physical activity uptake among White and South Asian older adults: Experiences of young older adults
}

\author{
Maria Horne $^{\mathrm{a}, *}$, Dawn Skelton ${ }^{\mathrm{b}, 1}$, Shaun Speed ${ }^{\mathrm{a}, 2}$, Chris Todd ${ }^{\mathrm{a}, 3}$ \\ ${ }^{a}$ The University of Manchester, Faculty of Medical and Human Sciences, School of Nursing, Midwifery and Social Work, Manchester, M13 9PL, England, UK \\ ${ }^{\mathrm{b}}$ Glasgow Caledonian University, HealthQuest, School of Nursing, Midwifery and Social Work, Glasgow, G4 OHB, Scotland, UK
}

\section{A R T I C L E I N F O}

Article history:

Received 17 November 2008

Received in revised form 23 March 2009

Accepted 4 April 2009

\section{Keywords:}

Exercise

Physical activity

Older adults

White/South Asian

Primary health care

Qualitative research

\begin{abstract}
A B S T R A C T
Objective: To explore the influence of primary health care professionals in increasing exercise and physical activity among 60-70-year-old White and South Asian community dwellers.

Method: Fifteen focus groups and 40 in-depth interviews with community dwelling White and South Asian 60-70-year olds. The sample was selected to include people with very different experiences of participation and non-participation in exercise and physical activity. Data were analysed using framework analysis.

Results: Primary health care professionals' advice and support was found to be a motivator to the initiation of exercise and physical activity. However, this was usually in relation to advice on weight reduction, cardiac conditions and mobility issues, but not generally to improve or increase activity levels. An underlying attitude of genuine interest and empathy was valued and shaped decisions about initiating and/or increasing activity levels.

Conclusion: Primary health care professionals should be encouraged to show interest and empathy with older people about the positive benefits of exercise and physical activity to them individually. This advice needs to be tailored to the older adult's symptoms.

Practice implications: Primary health care professionals need to be able to provide specific advice as to the quantity (frequency, duration, intensity and type) of exercise or physical activity to undertake. Practitioners need to listen to their patients' needs, show empathy and avoid ageism during consultations.
\end{abstract}

(c) 2009 Elsevier Ireland Ltd. All rights reserved.

\section{Introduction}

Physical inactivity is a major public health problem. Regular physical activity confers many substantial health benefits for older adults [1] and is a key determinant of good health. However $40 \%$ of over $50 \mathrm{~s}$ in the UK report less physical activity than is recommended [2]. Among 55-64-year olds, 32\% of men and 21\% of women reach current physical activity recommendations [3]. Sedentary behaviour is even more common among South Asians

\footnotetext{
* Corresponding author at: School of Nursing, Midwifery and Social Work, The University of Manchester, Jean McFarlane Building University Place, Oxford Road, Manchester, M13 9PL, UK. Tel.: +44 0161306 7680; fax: +44 01613067707.

E-mail addresses: maria.horne@machester.ac.uk (M. Horne),

dawn.skelton@gcal.ac.uk (D. Skelton), shaun.speed@manchester.ac.uk (S. Speed), chris.todd@manchester.ac.uk (C. Todd).

1 Tel.: +44 $01413318792 / 07976$ 538809; fax: +44 02089987672.

2 Tel.: +440161306 7694; fax: +440161306 7707 .

3 Tel.: +440161306 7865; fax: +440161306 7707 .
}

[4] and may contribute to their increased risk of coronary heart disease and stroke mortality, as well as a greater prevalence of diabetes [3].

The National Institute of Clinical Excellence (NICE), a UK independent organisation responsible for providing national guidance on promoting good health and preventing and treating ill health, recommends that primary health care practitioners should take the opportunity, whenever possible, to identify inactive adults and advise them to aim for 30 min of moderate activity on 5 or more days of the week [5]. Primary health care professionals are considered ideally placed to influence levels of activity in older people because of their access and contact with members of the general population [6]. In particular, General Practitioner (GP) counselling has been identified as a motivator to initiate activity among older adults [7] and is effective in increasing physical activity in the short term [8]. Hence, health professionals can be effective advocates of physical activity.

The idea that GPs could take a greater role in initiating the referral process for a variety of conditions has long been recognized 
[9]. Indeed, it is essential that physicians take the lead in motivating their older sedentary patients to adopt an active lifestyle [10]. Referral for supervised exercise by primary health care professionals' in general has been explored among general patient populations [11], and a National Quality Assurance for Exercise Referral has been published [12]. Primary health care professionals' generally have an influence in promoting regular physical activity among older adults and the effectiveness of this has been reported elsewhere [13,14]. Although many important influences have been identified, there still remains a need to identify specific variables among subgroups of the ageing population [15]. For example, few studies have looked at how primary health care professionals influence physical activity participation among young older adults, i.e. those aged 60-70 years [16-18] and little is known about South Asian young older adults' participation in physical activity [18-20]. Working with those entering old age could potentially produce substantial health and social benefits. Indeed, it has been argued that health promotion initiatives that encourage people to become more physically active should be targeted at those who are about to retire [21]. If primary health care professionals are to help reduce the burden of chronic disease in old age, then looking at how they may influence White and South Asian young older adults' participation in physical activity requires further exploration.

This qualitative study aims to report findings that demonstrate the influence of primary health care practitioners in encouraging physical activity uptake by using the experiences of community dwelling 60-70-year-old White and South Asian older adults. The data provides clear examples of how primary health care practitioners could and should present information about physical activity to young White and South Asian older adults in order to persuade them to take part and adhere to a regular physical activity programme, which could ultimately improve their health. We argue that practitioners should understand how exercise messages from the primary health care practitioners is given and perceived by young older adults, for example as primary or secondary prevention, as this may motivate or de-motivate young older people in the decisions they make about initiating exercise or physical activity.

\section{Method}

\subsection{Design}

An ethnographic approach [22] was used to obtain in-depth understanding of older adults' attitudes and beliefs about the initiation and maintenance of exercise and physical activity.

\subsection{Setting and participants}

Adults aged 60-70 years, from both White majority and South Asian ethnic minority groups, were recruited in the North West of

Table 1

Topic areas covered in focus groups and interviews.

Focus group topic areas

Personal meaning of exercise and physical activity and how they differ General exercise and physical activity history and current levels of activity Department of Health recommendations for regular activity and do they feel they achieve these levels of activity

Types of exercise/physical activity is appropriate for 60-70-year olds Preferred types of exercise and physical activity

Help and hinder factors to

(a) Undertaking

(b) Adhering to exercise and physical activity
England to focus groups and interviews from a period of fieldwork observation in a number of statutory and voluntary leisure and social centres. A purposive sampling strategy was employed to include adults with very different experiences in terms of health and of participation or non-participation in physical activity (regularly active to sedentary). The area had a significant first generation immigrant South Asian community and the purposive sampling method ensured people from South Asian descent were actively recruited to the study. People were offered either a focus group or individual interview depending on their personal preferences.

\subsection{Data collection}

Initially, older adults were recruited to focus groups to assess the range and variations of experiences that White and South Asian older adults had in relation to primary care practitioners influence in encouraging physical activity. A topic guide (Table 1) provided a flexible framework for the focus groups. In-depth interviews were subsequently conducted to accommodate older adults who were not necessarily a part of formal exercise and physical activity groups; those who did not feel happy to speak in a group collectively and to gain breath and depth of the themes highlighted in focus group discussions. An interview guide provided a flexible framework for the interviews (Table 1) and allowed for simultaneous data collection, analysis and interpretation, which is usual in qualitative research [23].

When working with minority groups it is important to use a local interpreter for linguistic accuracy and fluency, as linguistic diversity can exist within communities and dialects vary between areas [24]. Therefore, three local interpreters were used to interpret, translate and assist in interviewing and with the facilitation of the focus group discussions-one female, who could speak and translate Mirpuri Punjabi, one male who could speak and translate Mirpuri Punjabi and one female who could speak and translate in both Punjabi and Gujarati. Interpreters were used for all five focus groups and for 15 out of the 17 interviews.

Real time translation [25] was used during focus groups and interviews. This process involved the interpreters asking questions (lead by researcher $\mathrm{MH}$ ), then interpret and translate verbatim back to the interviewer after one person had spoken, or, if the conversation was flowing, to translate to the researcher when the flow of conversation came to a natural pause. This allowed the interviewer to guide, redirect discussion and probe further issues raised from the discussion via the interpreter.

For both focus groups and interviews, the interpreter would transcribe the tape into an English language transcript. The tape and transcription were then given to another native speaker, a multilingual link worker, to assess the accuracy of transcription provided by the original interpreter and agree a 'correct' version of the text. This was necessary to ensure the validity of 'correct'
Interview topic areas

Meaning of exercise and physical activity and how they differ General exercise and physical activity history and current levels of activity Department of Health recommendations for regular activity and do they feel they achieve these levels of activity

Beliefs about current levels of activity Motivators/de-motivators to

(a) Undertaking and

(b) Adhering to exercise or physical activity

Older adults perceptions of prevailing societal attitudes and beliefs about

(a) Older people undertaking exercise and physical activity and

(b) How this might influence their activity levels

Beliefs about aging, exercise and physical activity 
interpretations before any data analysis could take place. This pragmatic approach to accessing culturally specific data has support in the literature [25].

\subsection{Ethics}

Ethical approval was granted by the local NHS Research Ethics Committee. All consent forms and study information sheets were translated for South Asian participants and interpreters were used during 15 of the 17 interviews and all five focus groups. Names in the transcripts have been changed to maintain anonymity.

\subsection{Data analysis}

Data analysis and classification followed the framework approach [26]. This method of analysis was specifically designed to facilitate systematic analysis of qualitative data and has the ability to summarise and classify data within a thematic framework. Data analysis and collection were undertaken simultaneously. The themes were compared and contrasted within and across groups. The ATLAS/ti5.0 [27] qualitative analysis software programme assisted in coding, cross-referencing, storage and retrieval of data.

The original objective of the study was to look at attitudes of White and South Asian people and compare them. However, as data analysis progressed, it became clear that when talking about contacts with health care professionals there were few differences based on ethnicity. The analysis did reveal that there were positive and negative factors influencing the uptake and adherence to exercise and physical activity resulting from contact with health care professionals and these factors are the focus of this paper.

\section{Results}

Fifteen focus groups, lasting between 1 and $2 \mathrm{~h}$ and consisting of between three to twelve older adults and 40 in-depth interviews, lasting between 30 and $90 \mathrm{~min}$ (Table 2), were conducted by the principal researcher $(\mathrm{MH})$.

Participants were categorised as active, less active and sedentary on self-reported levels of physical activity using the

Table 2

Participant characteristics from focus groups.

\begin{tabular}{|c|c|c|}
\hline Characteristics & Focus groups & Interviews \\
\hline \multicolumn{3}{|l|}{ Age (years) } \\
\hline Mean & 66.1 & 65.0 \\
\hline Range & $60-70$ & $60-70$ \\
\hline Characteristics & Focus groups $n(\%)$ & Interviews $n(\%)$ \\
\hline \multicolumn{3}{|l|}{ Sex } \\
\hline Male & $30(34.5)$ & $16(40)$ \\
\hline Female & $57(65.5)$ & $24(60)$ \\
\hline \multicolumn{3}{|l|}{ Ethnicity } \\
\hline White & $58(66.7)$ & $23(57.5)$ \\
\hline South Asian & $29(33.3)$ & $17(42.5)$ \\
\hline \multicolumn{3}{|l|}{ Marital status } \\
\hline Married/cohabiting & $61(70)$ & $27(17.5)$ \\
\hline Widowed & $17(19.5)$ & $11(27.5)$ \\
\hline Divorced & $4(4.6)$ & $1(2.5)$ \\
\hline Single & $5(5.7)$ & $1(2.5)$ \\
\hline \multicolumn{3}{|l|}{ Level of activity ${ }^{\mathrm{a}}$} \\
\hline Active & $18(45)$ & $38(43.7)$ \\
\hline Less active & $13(32.5)$ & $38(43.7)$ \\
\hline Sedentary & $9(22.5)$ & $11(12.6)$ \\
\hline
\end{tabular}

a Using DH guidelines of regular activity [1] and adding a less active category.
Department of Health guidelines for regular activity [1] where active constitutes $30 \mathrm{~min}$ of at least moderate intensity physical activity a day, on 5 or more days a week and less than 30 min a week is deemed as sedentary [1]. However, the less active category was added as the distinction between active and sedentary were too extreme. This categorisation was added to see if there were any similarities or differences between the groups.

Three main themes were identified during the analysis-advice and support, preventative health promotion and information needs.

\subsection{Advice and support}

\subsubsection{Physician advice and support}

Both White and South Asian older adults described physician advice and support to be a motivator for initiating exercise and physical activity. However, this advice was reportedly given in relation to advice on weight reduction, cardiac conditions and mobility issues and not to improve or increase activity levels per se:

'... it was only when I started having problems again with my legs that the doctor said well I think you had better go on fitness for life, because you are putting weight on' (I22: White female, 63 yrs: Active).

'The doctor advised me that the more movement I can do with my body it will keep me better...because my back was stiff and everything and the doctor said that the more movement I can do in the gym the better' (I27: South Asian female, 60 yrs: Less active).

Despite the fact that these participants had experienced previous problems of a similar nature, the recommendation for exercise came as treatment, after they became ill again, rather than as a preventative measure or to increase general activity levels. Nevertheless, it was a motivator in these cases.

\subsubsection{Support from others}

Reportedly, the support offered by primary health care professionals was often not in itself sufficient to motivate older people to perform exercise and physical activity. Older adults within this study commented on the personal attributes and support they received from instructors and/or facilitators of exercise and others in physical activity groups. Having pleasant instructors was perceived to be a good motivator to continue with group based exercise and physical activity pursuits.

‘... if you get somebody pleasant [instructor] you know, it does make a difference as well. . If you had a bad instructor that was a bit well, not a nice personality... it would put you off...' (S1: White female, 62 yrs: Active).

'Well X [facilitator] makes you go and do it!' (BS1: South Asian female, 60 yrs: Active).

Likewise, lack of instructor support to teach and lead them through routines safely resulted in people terminating the activity:

'The nurse gave me a prescription for exercise. I took it down to $X$ Street but there is no supervisor for the gym and there are only two machines. So I stopped going' (I25: South Asian male, 68 yrs: Sedentary).

Amongst less active older adults, where self-motivation and experience were low, other variables could contribute to both initiate and continue with exercise. Some older adults described 
requiring both intensive and structured support to ensure that they were doing exercise activities correctly.

'I would go to the gym if I had one-to-one... a personal trainer. If I'm doing all these things I'm thinking have I done enough or have I not done enough. . I need someone to tell me, "right now, you do six weeks of these and you will be really good and toned up". I need somebody to tell me and to reassure me and to tell me that I'm going to be good, otherwise I end up feeling "well this is a waste of time"... n need somebody to go into more detail with me' (D2: White female, 61 yrs: Less active).

'If somebody would work with me I would work out for 30 minutes' (SG35: South Asian female, 70 yrs: Less active).

Therefore, although primary health care professional advice provided the motivation to initiate exercise and physical activity, instructor support appears to be crucial for less active young older adults to maintain exercise and physical activity, particularly in regards to instruction, supervision and encouragement.

However, other less active participants did not necessarily require trained instructors, just someone to encourage and support them through the activity.

'Not necessarily an instructor but somebody there, you know, to say do this and that and that. You know, like you're a five year old child. Saying "come on, come on". . I need a bit of encouragement, because I put myself back [doesn't push himself]' (I33: South Asian male, 63 yrs: Less active).

In these situations, the role of peer mentors (exercise buddies) may be influential in encouraging and supporting individuals through activity programmes [16]. This may be important in helping young older adults to maintain exercise and physical activity in the long term. Interestingly, none of the participants in this study reported having a peer mentor. However, the development of peer mentorship programmes in the community has been successful in getting older adult's active and staying active [28].

\subsection{Preventative health promotion}

\subsubsection{No encouragement}

Some young older adults felt there was no positive encouragement provided by primary health professionals to help people maintain physical health and well-being. Indeed, some participants felt that primary healthcare practitioners were only interested and concerned once health problems were identified:

'There is encouragement if you have had a problem to get over it, but there is no encouragement if you haven't got a problem to not get a problem' (H7: White male, 67 yrs: Active).

This had the effect of impeding the progress of performing and or increasing exercise and physical activity, which when juxtaposed with the data presented earlier suggests that communication between primary health care practitioners needs to be proactive, ongoing, reinforced and supported.

\subsubsection{Being 'listened to' and avoidance of ageist attitudes}

There were important precursors that needed to be present before sedentary older adults could accept the motivational advice from GPs. Important among these were adequate medication control and a sense of being 'listened to'.

'... I get a lot of support off my doctor, she is marvellous and if one thing doesn't work she will try something else and if that doesn't work she will get you to somebody to see what they think. Because she said I want you to go there to make sure that I have got you on the right medication, she is really good. Like the other doctor, you always feel that he isn't listening because he is always staring at the computer all the time, but she sits and looks at you and listens' (I23: White female, 63 yrs: Sedentary).

For others, advice from the GP might be acted on if it came as a recommendation to prevent the deterioration of health:

'Well, I suppose if the doctor said your health will deteriorate a lot if you don't start doing something, then I would have to seriously consider it' (I10: White female, 62 yrs: Less active).

However, a few more active young older adults found that primary health care practitioners could exert an unhelpful influence on the perceptions of their ability to perform exercise and physical activity at 'their age'. This, reportedly, de-motivated them from performing exercise.

'I think sometimes the medical profession are too quick to look at your age and say "you've got to this age", there is a certain amount of luck in it and him up there is playing a part, but I think sometimes they are too quick to jump in and say, "oh well it's deterioration" and that de-motivates people [to exercise] and I was de-motivated then...' (H7: White male, 67 yrs: Active).

'...what I am saying is that sometimes they [primary health care professionals] are too ready to quote age at you and more or less say that's it, rather than suggesting alternatives or suggest some way in which you can [do exercise]' (H3: White male, 66 yrs: Active).

Therefore, it becomes clear from these quotations that positive and encouraging information about exercise and physical activity, and the avoidance of 'ageist' remarks, should be a priority for all practitioners in the primary care setting.

\subsubsection{Exercise on prescription}

More active, young older adults reported having to self-initiate a referral to an exercise on prescription scheme:

'I mean my brother-in-law has had a heart attack and he gets a concession down here to come down. He hates coming, he likes the social side, but he doesn't like the exercise. But really there is an anomaly here isn't there, there is no encouragement for the people who haven't got a problem to not have a problem [had to ask the GP for exercise on prescription for himself]' (H7: White male, $67 \mathrm{yrs:}$ Active).

Of those young older adults who had no pre-existing medical problems, who would be considered fit, 10 reported that they had initiated the idea of a prescription for exercise with the GP; 20 reported that they had not even heard of the local scheme. This suggests that less active and sedentary young older adults are not all receiving a GP advice to exercise.

Although exercise on prescription was found to initiate exercise among some of the participants, the short-term nature of the prescription proved to be a barrier to continuing with exercise in the long-term:

'I mean quite a few years ago I got a referral from the doctors to go to fitness for life, and they stop it. They give you so long and then they stop it. Now perhaps if that had carried on, I might have carried on, but they only gave you so long and then stopped it' (I10: White female, 62 yrs: Less active). 
This quotation illustrates how exercise on prescription schemes can fail to maintain adherence to and continued attendance at an exercise programme. Therefore, more thought is required in planning for long-term motivation for adherence to exercise and physical activity once such schemes have come to an end. For instance, mail and telephone counselling may provide the external trigger required to continue the support necessary to motivate young older adults to maintain exercise and physical activity pursuits [17,29-32].

\subsection{Information needs}

\subsubsection{How much exercise and physical activity?}

It became apparent that quite a number of the participants were not aware of recommended activity levels.

\section{'. . do I need to do more exercise?' (RR6: White male, 65yrs: Less active).}

'Well, I think it [physical activity] probably would be better for my health, I'm sure the more you can do the better for your heart and everything like that, and I've got slight blood pressure, so I'm sure it would help that as well' (I10: White female, 62 yrs: Less active).

It was clear in this quotation that this woman had little idea about the level of exercise she should undertake or the effects that exercise would or could have on her long term health.

\subsubsection{Is it safe?}

Other participants in the study were unclear about how much exercise they were physically capable of doing with their existing health conditions, such as hypertension. This had the effect of impeding the progress of performing and or increasing exercise and physical activity. Furthermore, since the main reason for their consultation with the GP or Practice Nurse was for a medical issue, some young older adults would forget to ask whether they should or should not increase their activity levels:

'. . the only thing I don't know is that I have high blood pressure, and I wonder can I do it [jog]? I don't know, I keep on saying that when I go and see a practice nurse. . and ask her, but every time I go in I always forget to ask her. . . Because I don't know. . I suppose she would say, and she knows the state of my health, I would expect her to say to me, 'by all means yeah, in moderation, don't go like a rabbit'...' (I16: White male, 68 yrs: Active).

Like many others, this man did not appear to be aware of the risks and benefits of exercise for people with hypertension. Furthermore, this man second guessed what the primary health care practitioner would say. Importantly, the lack of information about the benefits of exercise was interpreted as a barrier by the participant.

\section{Discussion and conclusions}

The study demonstrates that primary health care practitioner advice appears to motivate young older adults, from both cultures, to increase physical activity as an adjunct to treatment rather than as a preventative measure. The experience of young older adults in this study is often that this advice came as counselling for secondary prevention (treatment of symptoms), rather than as a preventative measure as a way to increase general activity levels. Parallels are seen in the literature were clients are generally referred as a consequence of being obese, rather than for a 'lack of exercise' [33] and counselling often tended to be for secondary, rather than primary prevention [34].
GPs are generally a respected source of lifestyle advice, particularly for older people [35], who are relatively trusting and accepting of their GPs advice and decisions about their health care [36]. Indeed, participants who become physically active cited that having the doctor say exercise was important to their health was integral to their decision to exercise [35]. This generally came second to their own belief that exercise was important to their health, above any medical problems they were experiencing at the time [35]. GPs were also found to be an important source of motivation, in terms of information and encouragement, particularly if someone had an injury or illness [35]. Indeed, advice from the GP, leadership from a health care practitioner and peer support all influence adherence to an exercise programme [37].

The importance attached to primary health care practitioner's advice by young older adults in this study demonstrates that these practitioners have opportunities to promote physical activity to a large proportion of the population [38]. Hence, in routine primary care consultations, health care practitioners need to promote exercise and physical activity as a primary, as well as a secondary, prevention measure. This advice needs to be based on young older adults' potential motivation for doing exercise and physical activity at an individual level. The literature suggests that 2030 min of brief negotiation to increase physical activity is possibly more effective than similar attempts to persuade or coerce [13]. However, primary health care practitioners need to identify sources of social support available to the young older adult, so they are more likely to avail themselves of any exercise on prescription scheme or are more likely to maintain regular exercise and physical activity.

Many young older adults had not heard of the exercise on prescription scheme. Parallels are seen in the literature [14,38,39]. A telephone survey of community-dwelling older adults (mean age 74.9 years) found that only $48 \%$ of older adults recalled receiving a doctors suggestion to exercise [39]. Being younger, sedentary and having a higher body mass index were independently and positively associated with increased reports of having ever received advice to exercise [39]. Those older adults who were not thinking about changing physical activity behaviour and those who reported greater frequency of endurance exercise were less likely to recall receiving physician recommendation to exercise [39]. Qualitative studies suggest that very few older adults are referred on to an exercise referral scheme as a result of GP or nurse initiative, but were more likely to have approached primary care staff themselves to ask for a referral $[14,38]$. In general, older adults report that they were informed about the exercise referral schemes by friends or acquaintances [14]. This literature, however, generally refers to the post 65 age group. The findings from this current study, and some previous studies, support the view that primary care practitioners, in general, need to be more active in suggesting exercise and physical activity in consultations. It may be that primary health care practitioners require more education about the role of physical activity in the prevention and treatment of disease and fall prevention to be able to communicate the benefits to older people.

Although the evidence supports the view that people are motivated to exercise, in the short-term, as a result of receiving advice [40-42,29], the findings from this study suggest that advice in routine primary care consultations could also serve to demotivate older adults from exercising.

Primary health care practitioners are well positioned to provide advice and promote exercise and physical activity among young older adults but, from this study, we could not find evidence that they are doing so. Primary health care practitioners require training and support about the benefits of exercise and physical activity, even for frailer adults, and about the specificity of the messages they provide when discussing issues around increasing 
exercise and physical activity levels. A recent paper provides recommendations on ways to promote physical activity to older people [43]. At a community level, primary health professionals should liaise and work with statutory and voluntary agencies that complement and contribute to health promotion programmes designed to increase activity levels in young older adults. This may help to increase general population levels of physical activity.

\subsection{Peer mentors}

Participants in this study also required someone to encourage and support them through exercise and physical activity. In these situations, the role of peer mentors (exercise buddies) may be influential in encouraging and supporting individuals through activity programmes [16], which may be important in maintaining exercise and physical activity in the long term. None of the participants in this study reported having a peer mentor. The development of peer mentorship programmes in the community can be successful in getting older adults active and staying active [28].

\subsection{Strengths and limitations of the study}

The study utilised a number of steps to ensure rigour in its design. The cleaning of transcripts for accuracy, involving supervisors in the coding and analysis, and refining the interview guide to capture emerging themes facilitated the saturation of themes. Despite these strengths, it needs to be acknowledged that the data were collected as part of a PhD study exploring the attitudes and beliefs of 60-70year-old White and South Asian adults to initiate and adhere to exercise and physical activity. Therefore, this restricted the opportunity for further sampling limiting the potential to explore in detail the relationship between primary health care practitioners and young older adults in this area as well as longer term follow up.

\section{Conclusion}

This study provides useful insights into both the positive and negative experiences of young older White and South Asian adults when they are advised to increase exercise and physical activity after contacting primary care practitioners. How exercise messages from the primary health care practitioners is given and perceived by older adults, for example as primary or secondary prevention, may motivate or de-motivate older adults' decisions about initiating exercise or physical activity.

\subsection{Practice implications and future research}

With an increasing older population, primary health care practitioners need to be able to provide specific advice as to the quantity (frequency, duration, intensity and type) of exercise or physical activity to undertake. Practitioners need to listen to their patients' needs, show empathy and avoid ageism during consultations. Future research needs to purposively seek out primary health care practitioners' experience of providing advice to increase physical activity levels among young older adults from various cultures and focus on communication between young older adults, statutory and voluntary services in this area. A final, but noteworthy finding from this paper, is that there is little difference in this process between South Asian and White people.

\section{Conflict of interest}

None of the authors has any actual or potential conflicts of interest, including financial, personal, or other relationships with other people or organisations that could inappropriately influence or be perceived to influence this work.

\section{Acknowledgements}

The authors would like to thank the participants who volunteered their time to take part in this study and the University of Manchester School of Nursing, Midwifery and Social Work for funding this work through their fellowship scheme.

\section{References}

[1] Department of Health. At least five times a week. Evidence on the impact of physical activity and its relationship to health. A report from the Chief Medical Officer. London: Department of Health; 2004.

[2] Skelton D, Young A, Walker A, Hoinville E. Physical activity in later life. London: Health Education Authority; 1999.

[3] Department of Health. Health Survey for England 1998. London: The Stationary Office; 2000.

[4] Erens B, Primatesta P, Prior G. Health survey for England. The health of minority ethnic groups'99. London: Department of Health; 2001.

[5] Cohen-Mansfield J, Marx MS, Guralnik JM. Motivators and barriers to exercise in an older community-dwelling population. J Aging Phys Activ 2003;11:24253.

[6] Balde A, Figueras J, Hawking DA, Miller JR. Physician advice to the elderly about physical activity. J Aging Phys Activ 2003;11:90-7.

[7] NICE. Public Health Intervention Guidance no. 2. Four commonly used methods to increase physical activity: brief interventions in primary care, exercise referral schemes, pedometers and community-based exercise programmes for walking and cycling; 2006. Available at: http://www.nice.org.uk/guidance/ index.jsp?action=download $\& 0=31838$ [accessed on 30th June 2008].

[8] Morgan O. Approaches to increase physical activity: reviewing the evidence for exercise-referral schemes. Public Health 2005;119:361-70.

[9] Lawlor DA, Keen S, Neal RD. Increasing population levels of physical activity through primary care: GPs' knowledge, attitudes and self-reported practice. Fam Pract 1999;16:250-4.

[10] Nied RJ, Franklin B. Promoting and prescribing exercise for the elderly. Am Fam Physician 2002;65:419-26.

[11] Riddock C. Exercise referral systems. A review. Department of Health. London: The Stationary Office; 2000.

[12] Department of Health Exercise Referral systems: a national quality assurance framework. London: Department of Health; 2001.

[13] Hillsdon M, Thorogood M, White I, Foster C. Advising people to take more exercise is ineffective: a randomized controlled trial of physical activity promotion in primary care. Inter J Epidemiol 2002;31:808-15.

[14] Wormald H, Ingle L. GP exercise referral schemes: improving the patient experience. Health Educ J 2004;63:362-73.

[15] King AC. Interventions to promote physical activity in older adults. J Gerontol A Biol Sci Med Sci 2001;56A:36-46.

[16] Stewart AL, Mills KM, Sepsis PG, King AC, McLellan B, Roitz K, Ritter PL. Evaluation of CHAMPS, a physical activity promotion program for older adults. Ann Behav Med 1997;19:353-61.

[17] Stewart AL, Verboncoeur CJ, McLellan BY, Gillis DE, Rush S, Mills KM, Ritter P, Brown BW, Bortz WM. Physical activity outcomes of CHAMPS II: a physical activity promotion programme for older adults. J Gerontol Med Sci 2001;56A: M465-70.

[18] Sport England Understanding participation in sport: what determines sports participation among recently retired people?; 2006 Available at: http:// www.sportengland.org/recently_retired_full_report_january_2006.doc [accessed on 12th January 2008].

[19] Rai DK, Finch H. Physical activity 'from our point of view'. Qualitative research among South Asian and black communities. London: Health Education Authority; 1997.

[20] Lawton J, Ahmad N, Hanna L, Douglas M, Hallowell N. I can't do any serious exercise: barriers to physical activity amongst people of Pakistani and Indian origin with Type 2 diabetes. Health Educ Res 2006;21:43-54.

[21] Berger U, Der G, Mutrie N, Hannah MK. The impact of retirement on physical activity. Ageing Soc 2005;25:181-95.

[22] Hammersley M, Atkinson P. Ethnography: principles in practice, 3rd ed., Abingdon: Routledge; 2007.

[23] Miles MB, Huberman AM. Qualitative data analysis: an expanded sourcebook, 2nd ed., Newbury Park, CA: Sage; 1994.

[24] Chiu LF, Knight D. How useful are focus groups for obtaining the views of minority groups? In: Barbour RS, Kitzinger J, editors. Developing focus group research. Politics, theory and practice. London: Sage Publications; 1999 p. 99-112.

[25] Esposito N. From meaning to meaning: the influence of translation techniques on non-English focus group research. Qual Health Res 2001;11:568-79.

[26] Ritchie J, Spencer E. Qualitative data analysis for applied policy research. In: Bryman A, Burgess RG, editors. Analyzing qualitative data. London: Routledge: 1994.

[27] Muhr T. ATLAS.ti 5.0 scientific software development [computer software] Thousand Oaks, London: Sage; 2004.

[28] British Heart Foundation. Senior Peer Mentoring Scheme; 2006. http:// www.bhfactive.org.uk/areas_of_interest/spm/champs.htm (accessed on 26th June 2007).

[29] King A. Role of exercise counselling in health promotion. Br J Sports Med $2000 ; 34: 80-1$. 
[30] Castro CM, King AC, Brassington GS. Telephone versus mail interventions for maintenance of physical activity in older adults. Health Psychol 2001;20:438-44.

[31] Stewart AL, Gillis D, McLellan B, Grossman M, Pruit L, Castrillo M, Santis J, Villela V, McSpadden S, Violet M. Tailoring a successful physical activity promotion program for seniors in diverse community settings. Ann Behav Med 2001;23(Suppl.):S109.

[32] Pinto BM, Friedman R, Marcus BH, Kelly H, Tennstedt S, Gillman MW. Effects of a computer-based, telephone-counselling system on physical activity. Am J Prev Med 2002;23:113-20.

[33] Lord LC, Green F. Exercise on prescription: does it work? Health Educ J 1995;54:453-64.

[34] Wee CC, McCarthy EP, Davis RB, Phillips RS. Physician counselling about exercise. J Am Med Assoc 1999;282:1583-8.

[35] Burton LC, Shapiro S, German PS. Determinants of physical activity initiation and maintenance among community-dwelling older persons. Prev Med 1999;29:422-30.

[36] Herve C, Mullet E, Sorum PC. Age and medication acceptance. Exp Aging Res 2004;30:253-73.
[37] Grove NC, Spier BE. Motivating the well elderly to exercise. J Commun Health Nurs 1999;16:179-89.

[38] Hardcastle S, Taylor AH. Looking for more than weight loss and fitness gain: Psychosocial dimensions among older women in a primary-care exercisereferral program. J Aging Phys Activ 2000;9:313-28.

[39] Damush TM, Stewart AL, Mills KM, King AC, Ritter PL. Prevalence and correlates of physician recommendations to exercise among older adults.. J Gerontol Ser A Biol Sci Med Sci 1999;54:M423-7.

[40] McKenna J, Naylor P, McDowell N. Barriers to physical activity promotion by general practitioners and practice nurses. Br J Sports Med 1998;32:242-7.

[41] Hillsden M. Promoting physical activity: issues in primary health care. Int J Obes Relat Metab Dis 1998;22(Suppl. 2):S52-4.

[42] Elley C, Kerse N, Arroll B, Robinson E. Effectiveness of counselling patients on physical activity in general practice: cluster randomised controlled trial. $\mathrm{Br}$ Med J 2003;326:793-8.

[43] Yardley L, Beyer N, Hauer K, McKee K, Ballinger C, Todd C. Recommendations for promoting the engagement of older people in activities to prevent falls. Qual Saf Health Care 2007;16:230-4. 